\title{
Chinese Teachers’ Emotion Regulation Goals and Strategies
}

\author{
Shaoying Gong ${ }^{1,2}$, Xiaoyun Chai ${ }^{2,3}$, Ting Duan ${ }^{2}$, Liu Zhong ${ }^{2}$, Yongqing Jiao ${ }^{2}$ \\ ${ }^{1}$ Key Laboratory of Adolescent Cyberpsychology and Behavior (CCNU), Ministry of Education, Wuhan, China \\ ${ }^{2}$ Key Laboratory of Human Development and Mental Health of Hubei Province, School of Psychology, \\ Central China Normal University, Wuhan, China \\ ${ }^{3}$ Center for Mental Health Education, Hubei University of Automotive Technology, Shiyan, China \\ Email: gongsy_psy@163.com
}

Received August $16^{\text {th }}, 2013$; revised September $14^{\text {th }}, 2013$; accepted October $16^{\text {th }}, 2013$

Copyright (C) 2013 Shaoying Gong et al. This is an open access article distributed under the Creative Commons Attribution License, which permits unrestricted use, distribution, and reproduction in any medium, provided the original work is properly cited.

\begin{abstract}
This study aimed to explore Chinese teachers' emotion regulation goals and strategies used before, in, and after classroom teaching. Thirty-four teachers from elementary, middle and high schools were interviewed with semi-structure questionnaire. Chinese teachers' goals for regulating emotions included achieving instructional goals, decreasing the negative impact of emotions on student learning, confirming the professional and ethical norms, maintaining teachers' and students' mental health, keeping positive emotional images, and nurturing good teacher-student relationships. Teachers used various antecedent-focused and response-focused strategies to control their emotions before, in, and after class. In general, Chinese teachers used response-modulation most frequently, followed by cognitive changes in and after classroom teaching. These findings have implications for productive delivery of education service, teacher training and policy-making.
\end{abstract}

Keywords: Emotion; Emotion Regulation; Emotion Expression; Teacher

\section{Introduction}

\section{Teachers' Emotion}

Teaching is an occupation of care, and emotion is its core (Hargreaves, 1998). Teachers' emotional life is very rich. In school, teachers experience positive emotions such as happiness, joy, pride, and enthusiasm; and negative emotions, including anxiety, anger, frustration, disappointment, dissatisfaction, and shame (Bullough, 2009; Coates \& Thoresen, 1976; Hargreaves, 1998, 2000, 2005; Hosotani, 2011; Sutton, 2007; Sutton \& Wheatley, 2003; Van Veen, Sleegers, \& Van de Ven, 2005). These emotions result from various factors, including students' performance and progress, teachers' teaching, relationship with principal, colleagues, students and parents, or education reform, and so on. Teachers' emotions play an essential role in teachers' instructional behavior and students' learning and emotion (Frenzel, Goetz, Stephens, \& Jacob, 2009; Kunter et al., 2008; Skinner \& Belmont, 1993), and thus influence the attainment of educational goals. It is necessary for teachers to regulate their emotions, especially negative emotions, to achieve their instructional goals. Sometimes they suppress or cover their anxiety, anger, and frustration (Sutton, 2004); sometimes they may pretend to be happy. So, teaching is an emotional practice, which needs not only emotional understanding but also includes emotional "labor" (Hargreaves, 1998).

Research has found that Chinese teachers used emotion labor strategies in work situation, but they used deep acting more frequently than surface acting (Yang \& Li, 2009; Liu, 2007; Tian, Zhou, \& Chen, 2009), which suggests that teachers regulate their emotions frequently. However, few studies directly explore teachers, especially Chinese teachers’ emotion regulation. This study aims to investigate which strategies Chinese teachers use during teaching and why they regulate their emotions, to provide new information about teachers' emotion regulation in Chinese culture.

\section{Emotion Regulation Strategies}

Teaching is an intentional and interactive activity. It's time for a teacher to regulate his/her emotion when his/her emotion is inconsistent with the expected goals. Emotion regulation means the processes by which individuals influence which emotions they have, and when and how to experience and express those emotions (Gross, 1998, 2002; Richards \& Gross, 2000). Emotions are multi-component processes, involving behavioral, experiential, and physiological domains. Accordingly, emotion regulation involves changes in intensity, latency, duration, initiation time and offset of response in these componential processes (Gross, 1998).

Based on the process of emotion generation, Gross (1998) proposed emotion regulation theory in which emotion regulation was considered as a process correspondent to the process of emotion generation, one can regulate his emotion at every stage of emotion generation. Gross (1998) classified regulation strategies as antecedent-focused strategies which are used before appraisals give rise to emotional response tendencies and response-focused strategies which were used after emotions have been generated. Antecedent-focused strategies include situation selection, situation modification, attention deployment and cognitive change. Situation selection means one approaches or avoids certain people or situations on the basis of their likely 
emotional impact; situation modification refers that one modifies an environment so as to alter its emotional impact; attention deployment suggests that one turns attention toward or away from something in order to influence one's emotions; and cognitive change is one reevaluates either the situation one is in or one's capacity to manage the situation so as to alter one's emotions. If one uses strategies to regulate emotions which have been generated, these strategies are response-focused strategies which are also called response modulation strategies (Gross, 2002), including strategies that intensify, diminish, prolong or curtail ongoing emotional experience, expression, or physiological responding (Gross, 1998). People use antecedent-focused strategies to avoid emotions or change the value, intensity and duration of emotions. For example, an angry teacher stops teaching and lets the students do class work quietly to avoid his/her brewing anger. He/she can also diminish his anger by using response modulation, such as suppression.

One core feature of an emotion is that its generation is closely associated with one's goals (Gross \& Thompson, 2007). When an individual pays attention to a situation, and thinks it is relevant to his/her goals, emotions are generated. In this way the attainment of planned goals can be the goal of emotion regulation. In Sutton's study (2004), most America teachers considered emotion regulation as helpful for them to achieve the instruction goals, consistent with their beliefs and goals to construct good teacher-student relationships and their ideal emotion-image for a skilled teacher. Hosotani and his colleagues found (2011) besides shaping ideal teacher images, evoking children' emotions and conveying approval to children, getting children ready to listen or not wanting children to know teacher's emotions are high-quality Japanese elementary teachers' goals to express and regulate emotions in front of children. In the two studies, teachers came from different cultures and education systems, it is not clear whether culture and education systems have impacts on teachers' goals of emotion regulation. Our first question is what are the emotion regulation goals of Chinese teachers?

\section{Culture, Profession and Emotion Regulation}

Emotion expression and regulation is influenced by culture. The expression-rules for people from different countries are distinct (Matsumoto, Yoo, \& Nakagawa, 2008). For example, Western cultures encourage the expression of abundant positive emotions, while Oriental cultures (such as China) encourage expression of mild emotions, but never "high arousal emotions" (Mesquita \& Albert, 2007; Tsai, Knutson, \& Fung, 2006). These differences in emotion display rules can lead to differences in emotion regulation. In one study, Butler, Lee and Gross (2007) found that college students from Asian culture suppressed negative emotions more frequently than their American counterpart. Moreover, the suppression had less detrimental impact on Asian individuals than on American individuals. Cultures clearly can play a moderation role between suppression and its outcomes.

Professional rules and conventions also play a part in emotion expression and regulation. For example, professions which need employees to interact with people may ask their employees to express positive emotions and display a smiling disposition (Hochschild, 1983). It is true for Chinese employees to express emotions in accordance with the organization's display rules when interacting with clients (Hu \& Yang, 2009; Ma \&
Wang, 2011). Teaching also has its display-rules which teachers must follow in school (Zhang \& Zhu, 2008; Yin \& Lee, 2012). In school context, teachers may use general strategies as well as occupation-related strategies to regulate their emotions. Sutton (2004) reported that American middle school teachers used many preventive strategies, such as letting the entire class doing class work quietly, thinking of positive things, diverting attention, self-talk, and responsive strategies (e.g., pausing the class, taking a deep breath, controlling their facial expression and practicing reflecting) to help them regulate their emotions especially as a means to decrease negative emotions.

Chinese teachers express their emotions according the display rules by using natural expression and deep acting more than surface acting (Yang \& Li, 2009; Liu, 2007; Tian, Zhou, \& Chen, 2009). Using deep acting requires one changes his cognition, is related to cognition change strategy of emotion regulation. However, one need only modulate his expression to meet the organization's display rules, needn't change his emotion experience and cognition while using surface acting. Surface acting is associated with response modulation. To date, few studies directly explored strategies of emotion regulation in Chinese teachers. So, our second question is which strategies do teachers use to regulate their emotions in the Chinese cultural context and education system?

\section{Methods}

\section{Participants}

Participants were 34 teachers primarily from Hubei, three teachers were from Zhejiang, Jiangxi, and Hunan Province, People's Republic of China. Three were elementary school teachers, 11 were middle school teachers and 20 were high school teachers. The subject domains they taught included Chinese language, mathematics, English language, physics, biology, chemistry, and physical education. Fifteen were male. The mean years of teaching experience was 9.82, ranging from a half year to 26 years. Twenty two teachers got their bachelor degree, five got master degree, and seven teachers were enrolled in an Education Master's degree course in Central China Normal University in Wuhan.

\section{Semi-Structure Interview}

All the participants were interviewed with semi-structure questionnaire adapted from Sutton (2004), which included three main questions: 1) Which emotions do you experience in classroom teaching? Participants thought about and then talked by themselves and then selected names for the emotions from a list (happiness, satisfaction, surprise, relief, love, anxiety, anger, frustration, fear, disgust, disappointment, sadness). These are the emotions most often experienced by teachers (Coates \& Thoresen, 1976; Frenzel et al., 2009; Hargreaves, 1998; Sutton, 2007; Sutton \& Wheatley, 2003). 2) Do you ever try to regulate/control/pretend your emotions? 3) Why do you regulate your emotions?

\section{Procedure}

Four postgraduates interviewed all teachers and recorded their conversation with their consent in a quiet room in the university or in the participant's school. The interview lasted about from 20 minutes to 60 minutes. Then the records were tran- 
scribed into scripts word-by-word. The four postgraduates and the first author encoded the scripts based on Gross's classification of emotion regulation strategies which was classified as situation selection, situation modification, attention deployment, cognitive change, and response modulation (Gross, 1998).

\section{Results}

\section{The Emotion Regulation Goals}

Why do Chinese teachers regulate their emotions? What is the most important goal to regulate emotions? Teachers' answers to these two questions are diverse.

\section{Achieving Instructional Goals}

All the teachers interviewed thought the most important goal of regulation emotions was to accomplish instruction tasks optimally and to enhance instructional effects. A fifteen-year experienced teacher said: 'One of the most important goals was to make the teaching continue smoothly, to help me finish the tasks successfully and to achieve the present instructional goal.'

Many teachers said that the natural style was to express positive emotions which in turn were transmitted to students and which made their learning more effective. This phenomenon is emotional transmission (Frenzel, Goetz, L'dtke, Pekrun, \& Sutton, 2009). A teacher with five years experience said: "I express my positive emotions very naturally. When I am very happy and joyful, I will share it with my students. I let my positive emotions influence them.” A recent study has provided evidence for emotional transmission between teachers and students. Frenzel and colleagues (2009) found that teachers' joy could be transmitted to students, and predicted students' joy. However, teachers could also transmit their negative emotions to students. One female teacher with twelve years teaching experience reported: "If I am in negative emotion, my students will feel it."

However, some teachers reported expression of negative emotions was helpful to their instruction too. Two teachers upregulated their negative emotions so as to attract students' attention on their own inappropriate behaviors. Nine teachers thought that the expression of negative emotions was itself useful and appropriate for carrying out instructional tasks effectively. A first year teacher stated: "If I don't express when I am angry, students will not feel my anger and think that as the teacher I tacitly approve of their disruptive behavior." These teachers made use of the positive effect of negative emotions to manage the classroom in order to continue the teaching.

\section{Decreasing the Negative Impact of Emotion on Student Learning}

Nine teachers reported they control emotion to avoid influencing students learning negatively. Four of them said they shouldn't affect the whole class because of their bad emotion. Seven teachers thought bad emotion would result in students' lower motivation and achievement, reduce learning effectiveness, frustrate students' participation in class activities. For example, a beginning teacher said: "If you lose your temper, students will be inactive in answering questions or thinking." This reason is relevant to the goal of achieving instructional goals and teachers' roles of transmitter of knowledge. Achieving instructional goal doesn't only mean the teachers give class smoothly and finish all the instructional tasks, but also mean that students master the subject matter teachers impart and gen- erate positive attitude toward the subject. At the same time, Chinese teachers shoulder fundamental responsibility to ensure that all students progress (Hu, 2002). Controlling their emotions is helpful for teachers to achieve the goal-promoting students' learning and well-being.

\section{Following the Professional and Ethical Norms of Teaching}

Eight teachers said that regulating emotion was the requirement of professional and ethical norms. A third year teacher said: "The class is the class, and teachers have their rules and norms.” A teacher with eight years of experience said: 'A teacher is a rational human being, someone who can't afford to transmit negative emotions to students.' This is consistent with Yin and Lee's (2012) finding that controlling negative emotions is one of the professional requirements of teachers' work in Chinese culture.

Following the professional and ethical norms as a goal of emotion regulation of Chinese as well as western teachers embodied the view that a teacher should be a moral model of good conduct (Zhang \& Zhu, 2008). The society think a teacher should set a good example with his/her own conduct. They should lead students to live moral life. The double roles of teachers are embodied in the emotion regulation goals of teachers interviewed in this study. The first two regulation goals, achieving instructional goals and decreasing the negative impact of emotion on students learning, are the embodiment of teachers' role of transmitters of knowledge. And confirming the professional and ethical norms is related to teachers' role of moral models.

\section{Maintaining Students' Mental Health}

Eight teachers mentioned that to regulate negative emotions is helpful to keep or promote students' mental health. Teachers thought that they would defeat students' esteem and make students become overly sensitive if as teachers they could not well manage their own negative emotions. A teacher with 5-years experience said: "If a teacher doesn't regulate his/her emotions well it will have a bad impact on students' minds.” Another teacher worried that a teacher showing negative emotions without control would harm students. Teachers' beliefs about the harmful effect of their expression of negative emotions on students were supported by previous studies, which found that teachers' yelling made elementary school students feel small, guilty, embarrassed and hurt their feeling (Sutton, 2004; Thomas \& Montgomery, 1998).

This result is relevant to the current emphasis on students' mental health within the education system of China. The Ministry of Education of the People's Republic of China (2002) has determined that students' mental health is a primary goal of education and created policies to urge the promotion of a mental health educational curriculum. Many teachers have received training in mental health education intervention or have studied psychology courses; these regulatory policies and training could help the implementation of the relatively new mental health curriculum. Thus, to maintain and improve students' mental well-being has become an important goal of instruction and emotion regulation of Chinese teachers.

\section{Emotion Images}

Eight teachers thought that control emotion could keep good image in front of students. Three teachers reported teachers should be cool-headed. A female teacher with 16 years experi- 
ence said: "If I lose it, my image will be negatively influenced. As a teacher, you simply can’t afford to lose it.” Teachers are important models of socialization of emotion for students. That a teacher display positive emotion image will help the adolescents' socialization of emotion. Furthermore, saving face is a characteristic of Chinese culture where people control their bad or strong emotions to maintain the interpersonal harmonious (Gao, 2008). For example, one teacher said if he loses himself, he will lose his face in front of students.

\section{Nurturing and Maintaining Good Teacher-Student Relationship}

Four teachers reported that one of the important reasons for regulating emotions was to nurture good teacher-student relationships, thus improving the instruction. An experienced teacher said: "Of course, to regulate emotions is helpful for continuing instruction and establishing better teacher-student relationship." A ten year experienced teacher stated: "I want to become a popular teacher in students. I am in a middle school. If I am popular, my students can learn more, which in turn will be beneficial to them."

Teachers reckoned good teacher-student relationships as an important factor which influences students' learning. CorneilusWhite (2007) completed a meta-analysis study on the relationship between teacher-student relationships and student learning, and found that supportive teacher-student relationships that the student perceived as positive correlated with improved student performance and social outcomes. However, students' perception of a damaged teacher-student relationship had disadvantageous effect on students' motivation and adaptation. Nurturing good teacher-student relationships is not only a goal of emotion regulation, but also a means of achieving the instruction goals.

\section{Teachers’ Emotion Regulation Strategies}

We encoded the data based on Gross' (2002) process model of emotion regulation and classified all the regulation strategies into five categories: Situation selection, situation modification, attention deployment, cognitive change, and response modulation. Ninety-seven percent of teachers used two or more strategies to regulate their emotions. The following were the strategies teachers used before, in, and after class. All the strategies teachers reported were listed in Table $\mathbf{1 .}$

\section{Situation Selection}

When the cues leading to negative emotions emerged, one teacher selected a different situation to avoid the emotion before class, such as trading their class time with another teacher. In class, one teacher used the following strategy to regulate negative emotions: "I will walk to another group, and continue my class.”

\section{Situation Modification}

Before class, only one teacher reported that he would design some questions for the class when he was in a bad mood. In class, 18 teachers avoided the forthcoming negative emotions by modifying the situation, including adjusting the teaching tempo, pausing for a while and re-building a good atmosphere, telling a joke, or letting the class do class work quietly. A fifth year teacher said: "When I feel awkward, I will say a joke to build a good atmosphere, let everybody feel a little more comfortable. Change a way to continue the class. For example, I don’t teach, I let students do class work.”

\section{Attention Deployment}

Fourteen teachers reported diverting their attention to other things to avoid negative emotions before class. They stated that they would read the textbook, think of the instruction process, do things they liked, or think of happy things. One fifteen-year teacher said: "When things influence my mood before class, I will read the textbook, think of the teaching process. When I divert my attention, the influence will disappear.”

In class, ten teachers used this strategy to avoid or decrease their negative emotions, such as changing a topic, ignoring the current event. A teacher with fifteen years of experience reported: "One way is to shift the attention and not to pay attention to the event. Think of the whole class. When you pay your attention on classroom instruction, the emotion will become better."

After class, five teachers modulated their negative emotions by shifting their attention. They may do something they were interested in, think of happy things, or comment on and correct students' assignments.

\section{Cognitive Changes}

Four teachers changed their appraisal of things or students to avoid the negative effect of bad emotion on class before class. These strategies included thinking of the positive side of things, thinking of their students as "just children", or thinking that emotions before class should not influence the class. A sixteen-year teacher said: "I regulate the (bad) emotion well, I don't bring it to the class. The alternative way is to think of happy or good things. Think of the good side of everything.”

Before the emotion generated, nearly two thirds of teachers changed their cognition or reframed the meaning of things to avoid or decrease unpleasant emotions during class. Most of them changed their opinions on students or events. Some teachers walked in the classroom and engaged in self-talk or thought of students' advantages. For example, one teacher said: "One or two days is not enough for changing a student, fostering one's habit, or changing one's thought. You should gradually change them." Another eleven-year teacher said: "I think students are only young kids. To change them is a long-term education program. Then, sometimes when I know about the bad performers in the class, I think every student has advantages.”

After class, more than one thirds of teachers regulated their emotions generated in class. Reflecting on the instruction and finding solutions, changing their opinions on student learning, communicating with and learning from colleagues to identify a possible solution, and writing in a diary were some ways teachers used. One teacher with 16 years teaching experience said: "(about) very bad emotion, I will think whether or not I am being successful overall. I reflect on why I didn't get good return on my effort. I reflect on and want to change my teaching methods.”

\section{Responsive Modulation}

Before class, more than two fifths of teachers modulated their response to control emotions. Some teachers suppressed or vented negative emotions temporarily, by breathing deeply or exercising after the emotion was generated. Many teachers reported that they found a way to express positive emotions 


\section{S. Y. GONG ET AL.}

Table 1.

Chinese teachers' emotion regulation strategies before, in and after classroom ( $\mathrm{N}=34)$.

\begin{tabular}{|c|c|c|c|}
\hline Strategies & When & Number & Example \\
\hline \multirow{3}{*}{$\begin{array}{l}\text { Response } \\
\text { modulation }\end{array}$} & Before class & 14 & Hide in mind, breathe deeply, relax for a while, jump several times \\
\hline & In class & 29 & $\begin{array}{l}\text { Control and suppress down, sigh, breathe deeply, vent, pretend to be very sad, } \\
\text { conceal, hide, pause for a while, be calm for a second, clench fist }\end{array}$ \\
\hline & After class & 19 & $\begin{array}{l}\text { Pour out trouble to family members, friends and colleagues, complain, } \\
\text { be quiet for a while, vent by playing computer games }\end{array}$ \\
\hline \multirow{2}{*}{ Situation selection } & Before class & 1 & Change the class schedule \\
\hline & In class & 1 & Walk to another group and continue the class \\
\hline \multirow{2}{*}{ Situation modification } & Before class & 1 & Design some questions for the class \\
\hline & In class & 18 & Modulate the tempo, pause for a while and recreate a good atmosphere, tell a joke \\
\hline \multirow{3}{*}{ Attention deployment } & Before class & 14 & Read textbooks, think of the teaching process, talk with colleagues, do something I like \\
\hline & In class & 10 & Change to another topic, neglect the thing, let students do simple tasks \\
\hline & After class & 5 & Do something else, don't think of the thing, read books \\
\hline \multirow{3}{*}{ Cognitive changes } & Before class & 4 & Think of the positive side of a thing \\
\hline & In class & 21 & $\begin{array}{l}\text { Walk around and think, think that you can't change } \\
\text { kids in one or two days, express ideas }\end{array}$ \\
\hline & After class & 13 & $\begin{array}{l}\text { Reflect on, think over by myself, change the opinion on } \\
\text { student learning, ask advice from others }\end{array}$ \\
\hline
\end{tabular}

naturally and routinely. One fifth-year teacher said:

I expose my positive emotions naturally. When I am very happy or joyful, I will share them with my students, and hope my students are influenced by my positive emotions. I will not conceal my positive emotions. I will even express them exaggeratedly.

Some teachers would control positive emotions if the emotions were "too hot." Fifteen teachers down-regulated their positive emotions. One teacher even said he deliberately walked into the classroom peacefully or seriously so that students could not read his emotions.

In class, more than four fifths of teachers modulated their emotions, especially negative emotions. Most of them decreased negative emotions. The strategies they used included holding back, constraining, maintaining patience, covering up, concealing, keeping silent, venting as well as deeply breathing, sighing, calming, pausing, yelling, raising their voice, scolding, and gripping fists. For example, one seven-year teacher said: "Then when I was very angry, I had a deep breath to regulate. Sometimes when I was very, very angry, I turned to the blackboard, didn't look at them, and calmed myself.” Three teachers increased their positive emotions at times, another two upregulated their negative emotions particularly for sadness and anger. One teacher with 13-years experience said:

I seldom feel sad. If I am, I am pretending. In fact, I don't feel sad at all. This is a means of mobilizing the children.

For me, anger is a "pretend emotion.” It is not necessary to be angry. But, I intend to create an angry situation to give students a lesson.

The number of teachers who used responsive modulation after class to control their emotions comprised the largest group.
More than half of teachers modulated their emotions after their emotions were generated; talking to colleagues, families, and friends was the most often used strategy, followed by exercising, taking a walk, shopping, or playing computer games. One fifth-year teacher said: “After I went home, I talked with my family about the things which happened at school. It became OK after I talked, complained or grumbled. I would like to communicate with my colleagues, and they would only console me.”

\section{Discussion}

The present study explored emotion regulation goals and strategies of Chinese teachers. In short, Chinese teachers' goals of emotion regulation include 1) achieving instructional goals; 2) decreasing negative impacts of emotion on student learning; 3) confirming professional and ethic norms; 4) maintaining students' mental health; 5) keeping good emotional images; and 6) fostering good teacher-student relationship. Chinese teachers always or sometimes regulate their emotions, many teachers usually or always well-regulated their emotions. They adopted various strategies including every-day life and school-based strategies to control emotions before, in and after class. Response modulation was the most often used strategies in Chinese teachers, then cognitive changes.

Chinese teachers' goals of regulating emotions had some similarities to American teachers' in Sutton's study (2004). For example, achieving instructional goals, keeping positive emotion image and foster good teacher-student relationship are the common goals of emotion regulation of teachers in two countries. However, Chinese teachers had some different regulation goals including confirming the professional and ethical norms, decreasing the negative impacts of emotion on students learning, maintaining teachers' and students' mental health. These dif- 
ferences are related to Chinese culture and education system. In Chinese culture, teachers are considered as transmitters of knowledge and models of morality. They are asked to teach students learning as well as how to become a moral person, and to be responsible for students' learning, performance and conduct. The expectation of the society on teachers is internalized into teachers' professional norms which influence teachers' emotion expression and control. Furthermore, findings from the present study and previous studies (Sutton, 2004; Hosotani \& Imai-Matsumura, 2011) support the notion that teaching requires much emotional labor (Hargreaves, 1998, 2000). When modulating emotion response, a teacher usually needs to change only the expression, but not his emotion experience. While using cognition change strategies, a teacher's expression is consistent with the emotional experiences. Combining findings from different studies, it is obvious to find that there are similarities and differences in the goals of emotion regulation of teachers from different countries and grade level. Teachers from different countries and grade levels were similar in the goals of achieving instructional goals and keep ideal emotional images. But the difference in the goals of emotion regulation depends on the culture and grade level of teaching of teachers. Integrating the results from this and previous studies (Sutton, 2004; Hosotani \& Imai-Matsumura, 2011), we might conclude that teachers' emotion regulation goals were multifaceted. Moreover, achieving instructional goals were the most important forces at work for these teachers. Future research should consider how teachers' emotion regulation goals influence teachers' emotion regulation strategies, instructional behaviors and emotion well-being.

Chinese teachers used similar strategies to control their emotions before, in and after class with American teachers (Sutton, 2004). However, Chinese teachers were different from American teachers in emotion expression and the use of response modulation. In one study, $80 \%$ teachers always tried to increase their positive emotions including the expression of happiness; $65 \%$ always tried to decrease negative emotions such as anger or frustration (Sutton \& Harper, 2009). In the present study, fewer teachers (65\%) expressed positive emotions, and more teachers (74\%) down-regulated negative emotions. These teachers thought that the expression of negative emotions made them less effective. In another study, Hosotani and colleagues' (2001) found only 25\% Japanese high quality elementary school teachers expressed joy naturally. According to these studies, teachers in America express positive emotions more frequently while teachers from oriental cultures decrease negative emotions more often. The differences in emotion expression may reflect the essential difference in the overt display of classroom rules in different cultures. Collectivistic culture (such as Chinese and Japanese) stresses on harmony in groups, discourages expression of negative emotions and intense positive emotions (Matsumoto, 1989). However, Western cultures encourage individuals to access and express their positive emotions (Tsai et al., 2006). That some teachers decreased their positive emotions in this study provides new evidence for this basic conclusion. But, more quantitative evidence is needed to demonstrate whether or not there is a significant difference in emotion expression and regulation between teachers from Chinese culture and Western culture.

Chinese teachers in this study used response modulation most often in class, then cognitive changes. The frequency of response modulation and cognitive changes was $85 \%$ and $62 \%$ respectively, which was much higher than that of American teachers (50\% and 20\% respectively; Sutton, 2004). Chinese teachers had similar features with in-class emotions when regulating their after-class emotions. Fifty-six percent of teachers used response modulation and $38 \%$ of them changed their appraisal of stimuli. While $80 \%$ of American teachers in Sutton's study (2004) changed their cognition and appraisal of events to control their emotions after class, fewer teachers (37\%) modulated their responses. After combining the results of teacher emotion regulation during and following class, it is obvious that Chinese teachers use response modulation more often than those in the USA. This finding is consistent with that in Butler and colleagues' study (2007), who found that college students in collectivistic cultures (such as Asian) suppressed their negative emotions more often than those in individualistic cultures (e.g., USA). However, it is not entirely clear whether it is cultural context that influences teachers' emotion regulation strategies; therefore, it is crucial to examine the effect of cultural context on teachers' emotion regulation (Sutton \& Harper, 2009).

Distinct regulation strategies demonstrably have a different impact on individuals' interpersonal relationships. As already noted, nurturing a good teacher-student relationship is one of goals of emotion regulation. Some teachers decrease their negative emotions for this reason. However, shielding negative emotions from display may have deleterious social consequences. In one study, female college students' suppression had a negative impact on their own social interaction and dramatically reduced rapport and inhibited relationship formation (Butler, et al., 2003). However, culture may be a moderating factor between suppression and its negative consequences (Butler, Lee, \& Gross, 2007). In Chinese culture context, if teachers suppress their negative emotions, can they foster positive teacher-student relationships? Or do teachers who often repress their negative emotions have less healthy and more negative relationships than those who reappraise emotion stimulus? Which teachers are those who are more likely to suppress emotions? It is very necessary to explore the relationship between teachers' emotion, emotion regulation strategies in the future.

\section{Conclusion and Implications}

Teachers in the present study regulated their emotions for multifaceted goals. The most important goal was to achieve the planned instructional goals, then decreasing negative impacts of emotions on student learning and confirming professional and ethic norms. The last three goals were maintaining students' mental health, keeping good emotional images and fostering good teacher-student relationship. Future studies might explore the effect of culture on teachers' goals of regulation.

Before, during and after teaching, Chinese teachers used many strategies to regulate their emotions, and to modulate emotion response more frequently than to reframe cognition on students and events. Compared to American teachers, Chinese teachers suppressed their negative emotions more often and expressed positive emotions less. However, the difference in strategies of expressing and regulating emotion between Chinese and American teachers needs future research to provide clear quantitative evidence.

The findings from this study have some implications for influencing the efficiency and productive delivery of education services, teacher training and policy-making. First, Chinese 
teachers are usually well-trained in subject knowledge and teaching pedagogy, but they seldom receive formal training in effective emotion management/regulation. Teachers' emotion regulation is largely unexplored and has seldom been considered as important content in teacher education pedagogic training. But relevant training seems necessary to enhance teachers' awareness and strategies of emotion regulation and to ensure teachers' adoption of appropriate emotion strategies to facilitate teaching and learning. If teacher-preparation education courses consider emotion regulation as serious contenders in the content of the training programs, pre-service teachers and novice teachers will have a better chance to know more about how to regulate their emotions, and to be able to identify which are the factors that best influence emotion regulation strategies in classroom. Secondly, for new teachers entering teaching, how to improve their emotion regulation skills is very important for their teaching and classroom management. Teachers' emotion regulation strategies could influence their efficacy. In one study, Sutton and Knight (2006) found that reappraisal strategy was correlated with K-8 teachers' engagement and management efficacy. If new teachers have more understanding of and master effective regulation strategies, they may have higher teacher efficacy to teach, manage classroom and motivate students learning. Thirdly, Principal and other administrators supervise teachers' emotion and regulation that will be helpful for teachers to improve effective instruction and student learning. Many teachers interviewed in this study reported supports from principal and colleagues will help them decrease and regulate their negative emotions. Administrators creating a supportive work environment and atmosphere will be beneficial for teachers' instruction and emotion regulation. Finally, policy-makers need to consider the features of teaching, and make policies to maintain and improve teachers' emotion health and well-being. Some teachers interviewed in this study also said the education system (such as emphasis on exam and grades) is one of factors influencing their emotions and regulation. Previous studies reported that teachers' emotions and regulation strategies had important impact on teachers' emotion exhaustion (Chang, 2009; Tsouloupas et al., 2010). However, little attention was focused on teachers' emotion and regulation in educational policies and the definitions of teacher standards in China. Policy-makers should pay more attention to teachers' emotion and regulation and make policies more beneficial to teachers' emotional wellbeing, which is critical for teachers' whole wellbeing.

The present study has some limitations. The sample size is small, and the teachers are primarily from Central China and secondary schools. As mentioned, teachers' emotion and regulation strategies could be influenced by the grade level. Thus, it must be cautious in generalizing the present findings based on this small sample to the larger population of Chinese teachers. The results need to be replicated with larger samples and including teachers from different grade levels and areas and with different teaching experiences. The longitudinal studies are needed to explore the changes of teachers' strategies of emotion regulation with the teaching experience increasing. Secondly, although some findings seemed to associate with teachers' teaching experiences, the present study couldn't conclude the difference in emotion regulation among teachers with different teaching experience because of the small sample. Future exploration on the differences of regulation strategies among teachers with different experience is necessary.

It should be noted that the data presented here are qualitative, and thus the interpretations are descriptive. Although we adopted similar question in the semi-interview to Sutton' study (2004), there may be difference in interview process and encoding. The differences in goals and strategies between teachers in the two studies need more evidence. Furthermore, it is not clear which factors influence teachers' emotion regulation and what's the consequence of emotion regulation on teachers' behavior and students' learning. It is crucial to explore these questions in the future.

\section{Acknowledgements}

The research reported here was supported by a grant from the Social Sciences, Arts and Humanities Fund of the Ministry of Education (13YJA190005) and the Fundamental Research Funds for the Central Universities (120002040498).

The authors would like to thank Professor Caven S. Mc Loughlin of Kent State University for his review of the first draft, Panpan Zhang, Jiawei Li and Kuoteng Zhang for their assistance during interviewing teachers.

\section{REFERENCES}

Bullough, R. V. (2009). Seeking eudaimonia: The emotions in learning to teach and to mentor. In P. A. Schutz, \& M. S. Zembylas (Eds.), Advances in teacher emotion research (pp. 33-53). Dordrecht: Springer.

Butler, E. A., Egloff, B., Wlhelm, F. H., Smith, N. C., Erickson, E. A., \& Gross, J. J. (2003). The social consequences of expressive suppression. Emotion, 3, 48-67.

http://dx.doi.org/10.1037/1528-3542.3.1.48

Butler, E. A., Lee, T. L., \& Gross, J. J. (2007). Emotion regulation and culture: Are the social consequences of emotion suppression culturespecific? Emotion, 7, 30-48. http://dx.doi.org/10.1037/1528-3542.7.1.30

Chang, M. L. (2009). Teacher Emotional Management in the Classroom: Appraisals, regulation, and coping with emotions. San Diego, CA: Paper presented at the Annual Meeting of the American Educational Research Association.

Coates, T. J., \& Thoresen, C. E. (1976). Teacher anxiety: A review with recommendations. Review of Educational Research, 46, 159-184. http://dx.doi.org/10.3102/00346543046002159

Cornelius-White, J. (2007). Learner-centered teacher-student relationships are effective: A meta-analysis. Review of Educational Research, 77, 113-143. http://dx.doi.org/10.3102/003465430298563

Frenzel, A. C., Goetz, T., L’dtke, O., Pekrun, R., \& Sutton, R. E. (2009). Emotional transmission in the classroom: Exploring the relationship between teacher and student enjoyment. Journal of Educational Psychology, 101, 705-726. http://dx.doi.org/10.1037/a0014695

Frenzel, A. C., Goetz, T., Stephens, E. J., \& Jacob, B. (2009). Antecedents and effects of teachers' emotional experiences: An integrated perspective and empirical test. In P. A. Schutz and M.s Zembylas (Eds.), Advances in teacher emotion research (pp. 129-151). Dordrecht: Springer.

Gao, X. (2008). Teachers' professional vulnerability and cultural tradition: A Chinese paradox. Teaching and Teacher Education, 24, 154-165. http://dx.doi.org/10.1016/j.tate.2006.11.011

Gross, J. J. (1998). Antecedent-and response-focused emotion regulation: Divergent consequences for experience, expression, and physiology. Journal of Personality and Social Psychology, 74, 224-237. http://dx.doi.org/10.1037/0022-3514.74.1.224

Gross, J. J. (2002). Emotion regulation: Affective, cognitive, and social consequences. Psychophysiology, 39, 281-291. http://dx.doi.org/10.1017/S0048577201393198

Gross, J. J., \& Thompson, R. A. (2007). Emotion regulation: Conceptual foundations. In J. J. Gross (Ed.), Handbook of Emotion Regulation (pp. 3-24). New York: Guilford Press. 
Hargreaves, A. (1998). The emotional practice of teaching. Teaching and Teacher Education, 14, 835-854. http://dx.doi.org/10.1016/S0742-051X(98)00025-0

Hargreaves, A. (2000). Mixed emotions: Teachers' perceptions of their interactions with students. Teaching and Teacher Education, 16, 811-826. http://dx.doi.org/10.1016/S0742-051X(00)00028-7

Hargreaves, A. (2005). Educational change takes ages: Life, career and generational factors in teachers' emotional responses to educational change. Teaching and Teacher Education, 21, 967-983. http://dx.doi.org/10.1016/j.tate.2005.06.007

Hochschild, A. R. (1983). The managed heart. Berkeley, CA: University of California Press.

Hosotani, R., \& Imai-Matsumura, K. (2011). Emotional experience, expression, and regulation of high-quality Japanese elementary school teachers. Teaching and Teacher Education, 27, 1039-1048. http://dx.doi.org/10.1016/j.tate.2011.03.010

Hu, J., \& Yang, L. (2009). Emotional labor requirement and emotional exhaustion: A mediator analysis of emotional strategy (in Chinese). Psychological Sciences, 32, 423-426.

Hu, G. (2002). Potential cultural resistance to pedagogical imports: The case of communicative language teaching in China. Language, Culture and Curriculum, 15, 93-105. http://dx.doi.org/10.1080/07908310208666636

Kunter, M., Tsai, Y. M., Klusmann, U., Brunner, M., Krauss, S., \& Baumert, J. (2008). Students' and mathematics teachers' perceptions of teacher enthusiasm and instruction. Learning and Instruction, 18, 468-482. http://dx.doi.org/10.1016/j.learninstruc.2008.06.008

Liu, Y. (2007). Research on teacher's emotion work in elementary and middle school (in Chinese). Doctoral Dissertation in South West Normal University.

Ma, Y., \& Wang, T. (2011). Is emotional labor the same to all employees in the service industry? The moderating effect of negative affectivity and social skill (in Chinese). Economic Management, 33, 95-102.

Matsumoto, D. (1989). Cultural influences on the perception of emotion. Journal of Cross-Cultural Psychology, 20, 92-105. http://dx.doi.org/10.1177/0022022189201006

Matsumoto, D., Yoo, S. H., \& Nakagawa, S. (2008). Culture, emotion regulation, and adjustment. Journal of Personality and Social Psychology, 94, 925-937. http://dx.doi.org/10.1037/0022-3514.94.6.925

Mesquita, B., \& Albert, D. (2007). The cultural regulation of emotions. In J. J. Gross (Ed.). Handbook of emotion regulation (pp. 486-503). New York: Guilford Press.

Ministry of Education of China (2002). The Program of Action for Mental Health Education in Elementary and Middle School. http://www.moe.edu.cn/

Richards, J. M., \& Gross, J. J. (2000). Emotion regulation and memory: The cognitive costs of keeping one's cool. Journal of Personality and Social Psychology, 79, 410-424. http://dx.doi.org/10.1037/0022-3514.79.3.410

Skinner, E. A., \& Belmont, M. J. (1993). Motivation in the classroom: Reciprocal effects of teacher behavior and student engagement across the school year. Journal of Educational Psychology, 85, 571-581. http://dx.doi.org/10.1037/0022-0663.85.4.571

Sutton, R. E. (2004). Emotional regulation goals and strategies of teachers. Social Psychology of Education, 7, 379-398.

http://dx.doi.org/10.1007/s11218-004-4229-y

Sutton, R. (2007). Teachers' anger, frustration, and self-regulation. In P. A. Schutz, \& R. Pekrun (Eds.), Emotion in education (pp. 259-274). San Diego, CA: Academic Press. http://dx.doi.org/10.1016/B978-012372545-5/50016-2

Sutton, R. E., \& Harper, E. (2009). Teachers' emotion regulation. In L. J. Saha, \& A. G. Dworkin (Eds.), International handbook of research on teachers and teaching (pp. 389-401). New York: Springer. http://dx.doi.org/10.1007/978-0-387-73317-3 25

Sutton, R. E., \& Knight, C. C. (2006). Teachers’ emotion regulation. In A. V. Mitel (Ed.), Trends in Educational Psychology (pp. 107-136). Hauppauge, NY: Nova Publishers.

Sutton, R. E., \& Wheatley, K. F. (2003). Teachers' emotions and teaching: A review of the literature and directions for future research. Educational Psychology Review, 15, 327-358. http://dx.doi.org/10.1023/A:1026131715856

Thomas, J. A., \& Montomery, P. (1998). On becoming a good teacher: Reflective practice with regard to children's voices. Journal of Teacher Education, 49, 372-380. http://dx.doi.org/10.1177/0022487198049005007

Tian, X., Zhou, H., \& Chen, D. (2009). A survey on emotional labor of special education teachers (in Chinese). Chinese Journal of Special Education, 8, 50-56.

Tsouloupas, C. N., Carson, R. L., Matthews, R., Grawitch, M. J., \& Barber, L. K. (2010). Exploring the association between teachers' perceived student misbehaviour and emotional exhaustion: The importance of teacher efficacy beliefs and emotion regulation. Educational Psychology, 30, 173-189. http://dx.doi.org/10.1080/01443410903494460

Tsai, J. L., Levenson, R. W., \& McCoy, K. (2006). Cultural and temperamental variation in emotional response. Emotion, 6, 484-497. http://dx.doi.org/10.1037/1528-3542.6.3.484

Van Veen, K., Sleegers, P., \& Van de Ven, P. H. (2005). One teacher's identity, emotions, and commitment to change: A case study into the cognitive-affective processes of a secondary school teacher in the context of reforms. Teaching and teacher education, 21, 917-934. http://dx.doi.org/10.1016/j.tate.2005.06.004

Yang, L., \& Li, M. (2009). The relationship among emotion work strategies, characters and job satisfaction in primary and middle school teachers (in Chinese). Psychological Development and Education, 3, 89-94.

Yin, H.-B., \& Lee, J. (2012). Be passionate, but be rational as well: Emotional rules for Chinese teachers' work. Teaching and Teacher Education, 28, 56-65. http://dx.doi.org/10.1016/j.tate.2011.08.005

Zhang, Q., \& Zhu, W. (2008). Exploring emotion in teaching: Emotional labor, burnout, and satisfaction in Chinese higher education. Communication Education, 57, 105-122. http://dx.doi.org/10.1080/03634520701586310 